\title{
Impact of Reading Anxiety on Reading Comprehension Performance in ESL Classroom of Boys' Degree College Larkana, Sindh, Pakistan
}

\author{
Wazir Ali Kalhoro ${ }^{1} \quad$ Assistant professor: Shoukat Ali lohar ${ }^{2} \quad$ Intikhab Ahmed Panhwar ${ }^{3}$ \\ 1. MS scholar Mehran UET Jamshoro \\ 2. Associate Professor Mehran UET Jamshoro \\ 3. MS scholar Mehran UET Jamshoro
}

\begin{abstract}
This study investigates the impact of foreign language reading anxiety upon reading comprehension performance, the factors that affect comprehension performance, covering second language (L2). All Participants were Pakistani, studying English as a second language at government boys Degree College, Larkana, Sindh Pakistan. They were asked to fill the foreign language reading anxiety scale (FLRAS; Saito, Horwitz, \& Garza, 1999) was developed to measure reading anxiety in L2. Reading comprehension tests were used to investigate students' reading comprehension performance in L2. Correlation analysis indicated that effect of reading anxiety was significant on reading comprehension performance of the students, it can be stated that students of boys Degree College face considerable challenges in comprehending the topics written with English. Students are unable to comprehend topics and concepts as they did not merely have lack of expertise in reading meanwhile, understanding, and pronunciation is also some fundamental challenges that are challenging the reading comprehension of students. In addition, the study found students face considerable challenges in reading comprehension also because they fail to remember letters. It can be stated that challenges for the students in the form of pronunciation, remembering letters, understanding collectively or individually results in the lower self- esteem, confidence and increased reading anxiety. Further, Reading anxiety which is developed due to discussed challenges has a significant impact on foreign reading comprehension performance. The study suggests that because of low self-esteem and confidence, students dislike reading in an ESL classroom.
\end{abstract}

Keywords: anxiety, foreign reading anxiety, reading comprehension performance

DOI: $10.7176 / \mathrm{JEP} / 11-26-09$

Publication date:September $30^{\text {th }} 2020$

\section{Introduction}

Anxiety has a vital role during language learning. Previous research shows high level anxiety affects achievement and motivation. It is one of the affective factors that constitutes a great challenge to students' academic progress Sabbah, S. S. (2018). Anxiety must indeed have significant negative impact. It is generally defined as "a state of apprehension, a vague fear". It is very important to learn an extra language in both ways cognitively and emotionally Abu-Rabia*, S. (2004). Anxiety is a typical and emotional issue in the field of second language (L2) learning it has been related to teachers, researchers for a long time. A plethora of research has been done in language learning that concluded," Anxiety was a vital element during second language learning". (L2) Na, and Wei, (2007) More comprehensively, anxiety is disgusting process during conversation in the area of second language (L2) learning where a speaker is not completely an expert. It is typical cognitive form based on a plenty of factors which are related to "feelings of uneasiness, frustration, self-doubt, insecurity or apprehension and is intricately intertwined with self-esteem issues and natural ego-preserving fears”. Gardner, R. C., \& MacIntyre, P. D. (1993). When we look at skill-specific anxiety under focused, it is clear that most of work has been done on speaking anxieties of L2 learners. Recent Research regarding anxiety has unveiled skills other than speaking are clearly to cause anxiety reactions among L2 learners. An important module is "reading" on which less research has been done. Language is based on four modules like speaking, listening, writing and last one is reading. So, reading is essential and primarily requirement for any academic level and gives opportunities for learners. For example, if a student has not a good grip in reading, he/she will face difficulties and become failure entire social activities as well as academic career. Reader who has knowledge he/she does not mean that he is one who is deemed to understand the meaning and sense of the individual word that expresses verification of the structure and its surface is much tedious and text seems to be difficult and not understandable for students to tolerate them. Similarly the author, Cates, C. (1979) stated that "the aim of reading is not about the lexical identification to understand the meaning of the text" they must know about the relations of the text pertaining to sentence that exist in textual form. Further, Lien, H. Y. (2011) explained that in the area of second language learning had noted anxiety and reading tips as two vital factors that affect the reading comprehension performance of the L2 learners. Similarly, Bernhardt (2000, 2003, and 2005) mentioned the affective elements including anxiety might explain some variances in second language reading performance. From the second language learning perspective, it is seen 
that reading is more challenging task. With regards to the text the learners should deal with unrelated spelling structures, lexicons and syntax as well as sentence structure. Often, the researchers found that grounded difficulties to make sense and meaning from the text that has different rhetoric's require cultural contextual knowledge. Therefore, if foreign language (FL) learners are eager to achieve discomforts (Anxiety) as provoke job. Consequently, reading anxiety may have poor understanding and likewise it needs to be addressed by giving especial focus in the field or area of foreign or second language learnings. Nowadays, learning requires important role in the education world. Current Activities including reading and writing are called "literary tasks" Cameron (2001). Students who are associated with teaching and learning process during ESL classroom they must get good expertise in reading module. Most of students avoid to take part in reading task, eventually, they do not feel comfortable during reading task and they do not prefer reading task M. R., \& Hirsh, R. A. (2010). Avoiding in a reading task is considered symptoms of foreign reading anxiety in classroom Horwitz, Horwitz, \& Cope, (1986). In most of cases, foreign language reading anxiety does not have positive impact on reading comprehension and course Saito, Y., Garza, T. J., \& Horwitz, E. K. (1999).

\section{Literature review}

\subsection{Foreign Language Reading Anxiety}

Foreign language reading anxiety is identified when (ESL) learners become worried, nervous, and uncomfortable while reading English text. Zbornik (2001) explains reading anxiety disgusting feeling pertaining to reading English text that happens due to dislike in reading course. Reading anxiety was defined as a learner or people who have amazing emotional attachment regarding learner's actions or faith system. Likewise, the shape of dislikes are shown due to pressure from trainers or group pressure. It may enhance stress of of (ESL) learners while reading English text that affect their reading performance, peer reading and teacher's attitude. For instance, students make mistakes while pronouncing different words during reading task and other students laugh at them and teacher's behavior is rude on student's reading mistakes. This kind of behavior from other students and teachers prevent ESL learners to perform their reading skills. The proper attention is not given wrongly to foreign reading anxiety by teachers and practitioners as least anxiety-encourage, had not caught concentration of researchers. Saito et al. (1999) declares that foreign language reading anxiety distinguished type from language anxiety in general. During his research, a new scale to measure reading anxiety level was constructed, named foreign reading anxiety scale (FLRAS). Later Rajab, A., Zakaria, W. Z. W., Rahman, H. A., Hosni, A. D., \& Hassani, S. (2012) differentiated foreign reading anxiety from other general types of language anxiety that is related to verbal performance. Hence, reading anxiety is different type of anxiety in general. Further, reading is considered verbal performance whereas students try to show their interaction individually pertaining to text for instance, speaking, students always become uneasy during speaking to others. During reading course, the anxiety is found among ESL learners, but many a students are not found anxious during reading a text. Anxiety is called one factor that break the fluency of ESL learners while reading English course. Anxiety exactly exist when ESL students try to understand a non-native language text Saito et al. (1999).

\subsection{Potential Factors of Foreign Language Reading Anxiety}

The current research works with the idea introduced by Al-Shboul, M. M., Ahmad, I. S., Nordin, M. S., \& Rahman, Z. A. (2013). Two main elements were found in foreign reading anxiety for instance, personal elements and text format. In addition to this Alderson (2005) cited by Shariati \& Bordbar, 2009) they investigated elements which influence reading comprehension can understand among reader variables (internal to the reader) and text variables (external to the reader).

\subsection{Foreign Language Reading Anxiety Caused by Personal Factors}

This research introduce the idea given by Ahmed et al. (2013) that suggests two main elements regarding learners of non-native language become anxious about reading effect and afraid of making mistakes during reading in second language.

\subsection{Worry about Reading Effect}

To become anxious during reading is directly related to anxiety while reading aloud. Further, Jalongo \& Hirsh (2010) concludes that to become scarce while reading aloud is anxiety which does not give positive reaction. When reading aloud task is given to ESL learners among audiences they become anxious, loose fluency and feel difficulty to understand a text. When they are not able to control their confident feeling then it is not easy for them to understand central ideal of given text. Finally, they lost what they could read. Mostly, ESL learners become nervous during reading English course. Thus, it affects both reading comprehension and performance. Ahmed et al, (2013). 


\subsection{Fear of Making Error}

Worry is major factor associated with an idea of self-confidence. Most of studies supports it which gives thought that anxiety is directly involved with self-confidence latter is described as a positive module Brown, K., \& Brown, M. P. (2007). In most of cases, who have not enough confidence will feel fear to making mistakes in learning task. Therefore, feeling of fear to make mistakes will attract students towards reading English task.

\subsection{Foreign Language Reading Anxiety Caused by Text Features}

This research focuses on concept introduced by Ahmed et al (2013) that show three main factors under the idea of writing material for example, strange culture, unfamiliar task and strange vocabulary.

\subsection{Unfamiliar Culture}

Reading skills are considered crucial part of learning process among learners of non-native language, reading is not only considered interactions between reader and idea of author but also interaction between reader and background of the cultural history in the discourse writings Tomasello, M., \& Carpenter, M. (2005) not being a regular with English or the multi cultures might prevent learners reading comprehension course and resulted anxiety as a culture introduced material is foreign to them A., Zakaria, W. Z. W., Rahman, H. A., Hosni, A. D., \& Hassani, S. (2012).

\subsection{Unfamiliar Topic}

In research of Wallace (2001, cited in Kuru-Gonen, 2009) when favorite topic is not given to learners as a result they don't personally take interest to read. Consequently to become a good reader. A topic should be according to learner's interest and level. Finally, interest of learners will increase they will produce good result towards reading skills. This idea was given by Kuru-Gonen (2009) that unfamiliar topic will not reduce their foreign reading anxiety level.

\subsection{Unknown Vocabulary}

The study conducted by Rajab et al. (2012) strange words might affect student's comprehension performance show uneasiness that lead them towards worry. Ultimately, such kind of cases, English words entirely vary among Indonesian learners in form of pronunciations, because the words do not pronounce properly the actual pronunciation while reading English material. Indonesian learners have been facing this kind of problem and recognizing vocabulary itself has been major problem among Indonesian students. Furthermore, Shariati, M., \& Bordbar, A. (2011) declares that difficult words, mostly the actual meaning of expressions, make words hard among ESL readers.

Research questions

1. What difficulties are faced by college students during reading English text?

2 . What is the effect of reading anxiety on $\mathrm{L} 2$ reading comprehension performance?

3. What is the level of anxiety existing among college students in reading English text?

\section{Methodology}

The study that is reading anxiety and reading comprehension performance has been supported with the quantitative research design with the specific aim whether there is an impact of reading anxiety on the reading comprehension of ESL classroom. The findings of this study are on the basis of the several objectives that were made in order to examine the research phenomenon.

\subsection{Research Instrument}

The initial analysis of the study has been conducted on SPSS. Following this, the researcher has conducted confirmatory factor analysis (CFA) on SmartPLS which is followed by path analysis. The CFA analysis therefore, includes reliability analysis using composite reliability and Cronbach Alpha while the validity of the research's constructs have been computed using Average variance extracted (AVE), HTMT ratio and Fornell Larcker criterion. While the path analysis has been computed using structural equation model (SEM) model. In addition, the hypothesis formulated in previous chapters have been summarised in accordance with the results in this chapter and lastly, the discussion has been presented with respect to the attainment of research objectives and triangulation with the past studies regarding the commonalities and contrast.

\section{Research procedure \\ 3.2 Participants}

The total sample of the study was 160 participants from Boys Degree College that is located in district Larkana, Sindh, Pakistan. However, there were some missing values as well which the researcher has dealt and explained accordingly. Moreover, there were some outliers in the model as well which the researcher has removed and the 
process has been discussed accordingly.

\subsection{Instrumentation \\ The Questionnaire}

This questionnaire was developed by (Saito, 1999) named 'FLRAS'. That is based on 20 items in which five points LikertScale from strongly disagreed to strongly agreed was used. Thus, these items which are 20 only will collect data related to anxiety while reading English text and also other factor(s) that could be contributed for L2 Language anxiety during reading English text. To measure the performance I planned to develop an objective type questionnaire to be filled by students after reading a Passage.

\subsection{Data Analysis}

To ensure about levels of the anxiety producing in reading data was scrutinized by using computer statistical product SPSS (a detail method) and results for each item Was presented through-out this method which include mean notation (SDF) known as; Standard deviation and frequency during t-test will use to compare both selected groups of DEGREE COLLEGE students. To find out the connection of L2 reading and L2reading performance, the respondent's from first year course book in reading class was collected and calculated. Thus, using Pearson correlation coefficient $2^{\text {nd }}$ language anxiety of reading then was correlated with respondents' first year course book to secure (obtain) the correlation coefficient. While the path analysis has been computed using structural equation model (SEM) SmartPLS 3.0. In addition, the hypothesis formulated in previous chapters have been summarised in accordance with the results in this chapter and lastly, the discussion has been presented with respect to the attainment of research objectives and triangulation with the past studies regarding the commonalities and contrast.

\section{Conclusion}

The study that is reading anxiety and reading comprehension performance has been Supported with the quantitative research design with the specific aim whether there is an impact of reading anxiety on the reading comprehension of ESL classroom. The findings of this study are on the basis of the several objectives that were made in order to examine the research phenomenon. The study was centered on the hypothesis that was the effect of reading anxiety is significant on reading comprehension performance of the students studying in Degree College, Larkana. In order to determine the impact, different tests and analysis have been performed. On the basis of the path analysis, the $p$ value has been obtained as 0.000 which is convincingly lesser than the threshold 0.05 . In this context, the hypothesis of the study was accepted. In the study, there have been discussed several challenges that students with L2 I reading and comprehending topics. Based on the findings of this study, it can be stated that students of boys Degree College face considerable challenges in comprehending the topics written with English. As a result of this, students have been put in the state of anxiety where their reading comprehension has been significantly affected.

\section{REFERENCES}

Sabbah, S. S. (2018). Anxiety in learning English as a second language at a tertiary stage: causese and solutions. European Journal of English Language and Literature Studies, 6(1), 14-33.

Abu-Rabia*, S. (2004). Teachers' role, learners' gender differences, and FL anxiety among seventh-grade students studying English as a FL. Educational Psychology, 24(5), 711-721.

Gardner, R. C., \& MacIntyre, P. D. (1993). On the measurement of affective variables in second language learning. Language learning, 43(2), 157-194.

Cates, C. (1979). Beyond muddling: creativity. Public Administration Review, 39(6), 527-532.

Lien, H. Y. (2011). EFL Learners' reading strategy use in relation to reading anxiety. Language Education in Asia, 2(2), 199-212.

Brantmeier, C. (2000, 2003, 2005). Anxiety about L2 reading or L2 reading tasks? A study with advanced language learners. Reading, 5(2), 67-85.

Cameron, L. (2001). Teaching languages to young learners. Ernst Klett Sprachen.

Jalongo, M. R., \& Hirsh, R. A. (2010). Understanding reading anxiety: New insights from neuroscience. Early Childhood Education Journal, 37(6), 431-435.

Horwitz, E. K., Horwitz, M. B., \& Cope, J. (1986). Foreign language classroom anxiety. The Modern language journal, 70(2), 125-132.

Saito, Y., Garza, T. J., \& Horwitz, E. K. (1999). Foreign language reading anxiety. The modern language journal, 83(2), 202-218.

Zbornik, J. (2001). Test anxiety: Conceptualization and remediation strategies. Today's School Psychologist.

Saito et al. (1999) reported that they were un- able to "identify any material on first language reading anxiety.

Al-Shboul, M. M., Ahmad, I. S., Nordin, M. S., \& Rahman, Z. A. (2013). Foreign language anxiety and achievement: Systematic review. International Journal of English Linguistics, 3(2), 32.

Alderson, J. C. (2005). Diagnosing foreign language proficiency: The interface between learning and assessment. 
A\&C Black.

Brown, K., \& Brown, M. P. (2007). The Pilgrim and the Bee: Reading Rituals and Book Culture in Early New England. University of Pennsylvania Press.

Tomasello, M., \& Carpenter, M. (2005). Intention reading and imitative learning. Perspectives on imitation: From neuroscience to social science, 2, 133-148.

Rajab, A., Zakaria, W. Z. W., Rahman, H. A., Hosni, A. D., \& Hassani, S. (2012). Reading anxiety among second language learners. Procedia-Social and Behavioral Sciences, 66, 362-369.

Kuru-Gonen, S. I. (2009). The sources of foreign language reading anxiety of students in a turkish EFL context. Paper presented at the 5th WSEAS/IASME International Conference on EDUCATIONAL TECHNOLOGIES (EDUTE' 09), Spain.

Shariati, M., \& Bordbar, A. (2011). Interrelationship among foreign language reading anxiety, reading proficiency and text feature awareness in the university context. Iranian Journal of Applied Language Studies, 1(2), 179206.

Rahman, T. (2001). English-teaching institutions in Pakistan. Journal of Multilingual and Multicultural Development, 22(3), 242-261.

Hadidi, E., \& Bargezar, R. (2015). Investigating reading anxiety and performance on reading proficiency: A case of Iranian EFL learners. International Journal of Language and Applied Linguistics, 25, 50-57.

Zhou, J. (2017). Foreign language reading anxiety in a Chinese as a foreign language context. Reading in a foreign language, 29(1), 155-173.

Ghonsooly, B., \& Barghchi, B. (2012). An introspective study of L2 reading anxiety. Journal of Teaching Language Skills, 30(1), 65-98. 